\title{
Present and future ecological niche modeling of garter snake species from the Trans-Mexican Volcanic Belt
}

\author{
Andrea González-Fernández ${ }^{\text {Corresp., }}{ }^{1}$ ， Javier Manjarrez ${ }^{\text {Corresp., }}{ }^{1}$ ， Uri García-Vázquez ${ }^{2}$, Maristella D’Addario ${ }^{3}$, \\ Armando Sunny Corresp. 3 \\ 1 Facultad de Ciencias, Universidad Autónoma del Estado de México, Toluca, Estado de México, México \\ 2 Facultad de Estudios Superiores Zaragoza, Universidad Nacional Autónoma de México, Ciudad de México, Ciudad de México, México \\ 3 Centro de Investigación en Ciencias Biológicas Aplicadas, Universidad Autónoma del Estado de México, Toluca, Estado de México, México \\ Corresponding Authors: Andrea González-Fernández, Javier Manjarrez, Armando Sunny \\ Email address: andreagofe@gmail.com, jsilva@ecologia.unam.mx, sunny.biologia@gmail.com
}

Land use and climate change are affecting the abundance and distribution of species. The Trans-Mexican Volcanic Belt (TMVB) is a very diverse region due to geological history, geographic position, and climate. It is also one of the most disturbed regions in Mexico. Reptiles are particularly sensitive to environmental changes due to their low dispersal capacity and thermal ecology. In this study, we define the important environmental variables (considering climate, topography, and land use) and potential distribution (present and future) of the five Thamnophis species present in TMVB. To do so, we used the maximum entropy modeling software (MAXENT). First, we modeled to select the most important variables to explain the distribution of each species, then we modeled again using only the most important variables and projected these models to the future considering a middle-moderate climate change scenario (rcp45), and land use and vegetation variables for the year 2050 (generated according to land use changes that occurred between years 2002 and 2011). Arid vegetation had an important negative effect on habitat suitability for all species, and minimum temperature of the coldest month was important for four of the five species. Thamnophis cyrtopsis was the species with the lowest tolerance to minimum temperatures. The maximum temperature of the warmest month was important for $T$. scalaris and $T$. cyrtopsis. Low percentages of agriculture were positive for $T$. eques and $T$. melanogaster but, at higher values, agriculture had a negative effect on habitat suitability for both species. Elevation was the most important variable to explain $T$. eques and $T$. melanogaster potential distribution while distance to Abies forests was the most important variable for $T$. scalaris and $T$. scaliger. All species had a high proportion of their potential distribution in the TMVB. However, according to our models, all Thamnophis species will experience reductions in their potential distribution in this region. $T$. scalaris will suffer the biggest reduction because this species is limited by high temperatures and will not be able to shift its distribution upward, as it is already present in 
the highest elevations of the TMVB. 
1 Present and future ecological niche modeling of garter snake species from the Trans-

2 Mexican Volcanic Belt

3

4 Andrea González-Fernández ${ }^{\mathrm{a}^{*}}$, Javier Manjarrez $^{\mathrm{a}^{*}}$, Uri García-Vázquez ${ }^{\mathrm{b}}$, Maristella D’Addario ${ }^{\mathrm{c}}$,

5 Armando Sunny ${ }^{\mathrm{c}^{*}}$

6 aFacultad de Ciencias, Universidad Autónoma del Estado de México, Toluca, Estado de México,

7 México.

8 bFacultad de Estudios Superiores Zaragoza, Universidad Nacional Autónoma de México, Ciudad

9 de México, Ciudad de México, México.

10 'Centro de Investigación en Ciencias Biológicas Aplicadas, Universidad Autónoma del Estado

11 de México, Toluca, Estado de México, México.

12 *Corresponding authors: Andrea González-Fernández, e-mail address: andreagofe@gmail.com;

13 Javier Manjarrez, e-mail address: jsilva@,ecologia.unam.mx; Armando Sunny, e-mail address:

14 sunny.biologia@gmail.com.

15

16

Running title: Niche modeling of TMVB garter snakes.

17

18

19

20

21

22

23

24

25

26

27

28

29

30

31 
32 Abstract:

33

34 Land use and climate change are affecting the abundance and distribution of species. The TransMexican Volcanic Belt (TMVB) is a very diverse region due to geological history, geographic position, and climate. It is also one of the most disturbed regions in Mexico. Reptiles are particularly sensitive to environmental changes due to their low dispersal capacity and thermal ecology. In this study, we define the important environmental variables (considering climate, topography, and land use) and potential distribution (present and future) of the five Thamnophis species present in TMVB. To do so, we used the maximum entropy modeling software (MAXENT). First, we modeled to select the most important variables to explain the distribution of each species, then we modeled again using only the most important variables and projected these models to the future considering a middle-moderate climate change scenario (rcp45), and land use and vegetation variables for the year 2050 (generated according to land use changes that occurred between years 2002 and 2011). Arid vegetation had an important negative effect on habitat suitability for all species, and minimum temperature of the coldest month was important for four of the five species. Thamnophis cyrtopsis was the species with the lowest tolerance to minimum temperatures. The maximum temperature of the warmest month was important for $T$. scalaris and T. cyrtopsis. Low percentages of agriculture were positive for $T$. eques and $T$. melanogaster but, at higher values, agriculture had a negative effect on habitat suitability for both species. Elevation was the most important variable to explain T. eques and T. melanogaster potential distribution while distance to Abies forests was the most important variable for $T$. scalaris and T. scaliger. All species had a high proportion of their potential distribution in the TMVB. However, according to our models, all Thamnophis species will experience reductions in their potential distribution in this region. T. scalaris will suffer the biggest reduction because this species is limited by high temperatures and will not be able to shift its distribution upward, as it is already present in the highest elevations of the TMVB.

\section{Introduction}

61 Land use and climate change are affecting the abundance and distribution of species, altering 
63 2003; Cardinale et al., 2012; Kortsch et al., 2015; Nadeau, Urban \& Bridle, 2017). Both factors

64 are the main contributors to the global decline of reptiles (Ribeiro et al., 2009; Schneider-

65 Maunoury et al., 2016; Sunny, González-Fernández \& D’Addario, 2017). In fact, some studies

66 indicate that $20 \%$ of the world's reptile species are threatened (Böhm et al., 2013) because they

67 are particularly sensitive to environmental changes due to their low dispersal capacity and 68 thermal ecology (Huey, 1982; Castellano \& Valone, 2006; Ribeiro et al., 2009; Russildi et al.,

69 2016). Studies predicting biological responses to land use and climate change are therefore

70 necessary to assess the potential impacts of these changes and develop management decisions and conservation strategies (Jiménez-Valverde \& Lobo, 2007; Nadeau, Urban \& Bridle, 2017) to mitigate negative impacts. Information concerning species' distributions is essential in these cases (Liu, White \& Newell, 2013). Through species occurrence data and environmental information, we can generate environmental niche models that can be used to predict the location of particular areas where environmental conditions are favorable for the presence of the species of study (Suárez-Atilano, 2015).

The Trans-Mexican Volcanic Belt (TMVB) is a set of mountain ranges and volcanoes of different ages, aligned on a strip that crosses Mexico from west to east. It is a transition area between Nearctic and Neotropical regions that results in an overlap of biotas from both regions (Suárez-Atilano, 2015). Its geological history and geographic position make it a very complex area with 30 distinct climatic types and several different vegetation communities, such as coniferous forests (Pinus sp. and Abies sp.), oak forests (Quercus sp.), mesophyll forests, alpine pastures, subalpine scrub, and riparian vegetation zones (Espinoza \& Ocegueda, 2007). For these reasons, the TMVB has the second highest herpetological richness in Mexico and is the most important biogeographic region of the country in number of endemic amphibian and reptile species (Flores-Villela \& Canseco-Márquez, 2007; Sunny, González-Fernández \& D’Addario, 2017). Due to the complex characteristics of the TMVB, the montane taxa of this region have been exposed to a sky-island dynamic through climate fluctuations (Mastretta-Yanes, 2015), consequently, the high-altitude-adapted species could be especially vulnerable to climate change as they may be limited by future rising temperatures (Sunny, González-Fernández \& D’Addario, 92 2017). Moreover, the TMVB is one of the most disturbed regions in the country as it contains the 
93 biggest metropolitan areas of Mexico (CONAPO, 2010; Sunny, González-Fernández \&

94 D’Addario, 2017).

95

96

97

98

99

100

101

102

103

104

105

106

107

108

109

110

111

112

113

114

115

116

117

118

119

120

121

122

123

Garter snakes are among the most abundant snake species in North America (Rossman, Ford \& Seigel, 1996; de Queiroz, Lawson \& Lemos-Espinal, 2002) and they are distributed from Canada to Costa Rica (Rossman, Ford \& Seigel, 1996; Manjarrez, 1998; de Queiroz, Lawson \& Lemos-Espinal, 2002). However, we lack information on the ecology and current conservation status of most Thamnophis species that are endemic to, or primarily distributed in, Mexico (Manjarrez, Venegas-Barrera \& García-Guadarrama, 2007). They are also the most abundant snake genus in the TMVB (Flores-Villela, Canseco-Marquez \& Ochoa-Ochoa 2010), thus they have an important ecological role in the ecosystem (Montoya, Pimm \& Solé, 2006). These garter snakes also have great ecological plasticity in reproduction, feeding, and thermal ecology (Seigel, 1996).

For this study, we chose the five Thamnophis species that occur in the TMVB.

Thamnophis melanogaster is endemic to the Mexican Central Plateau. It is a semiaquatic species that inhabits the edges of water bodies and specializes in underwater foraging, preying on aquatic animals such as fish, tadpoles and leeches (Rossman, Ford \& Seigel, 1996). Thamnophis scalaris is endemic to high elevations across the TMVB (Rossman, Ford \& Seigel, 1996). It lives in grasslands and the periphery of forests, and feeds mainly on earthworms, although it can eat vertebrates such as mice and lizards (Uribe-Peña, Ramirez-Bautista, \& Casas-Andreu, 1999; Manjarrez, Venegas-Barrera \& García-Guadarrama, 2007). Thamnophis scaliger is a poorlyknown montane species, endemic to central Mexico (Rossman, Ford \& Seigel, 1996). It inhabits forests where it feeds on frogs, salamanders and lizards (Uribe-Peña, Ramrez-Bautista, \& CasasAndreu, 1999). Thamnophis cyrtopsis extends from the southern United States to Guatemala, although is mainly distributed in Mexico (Hammerson, 2013). It is an amphibian specialist in aquatic habitats from subtropical deciduous and mixed forests (Rossman, Ford \& Seigel, 1996). Thamnophis eques is widely distributed over the Mexican Plateau, reaching southern Arizona and New Mexico (Rossman, Ford \& Seigel, 1996). It is a generalist predator because it feeds on both aquatic and terrestrial prey - mostly frogs, tadpoles, and fish, supplemented by lizards and mice (Drummond \& Macías García, 1989; Manjarrez, 1998). 
124 Despite their widespread distribution and relatively high abundance in comparison to 125 other reptiles, this group has suffered critical reductions in the last 10 years (Canseco-Márquez \& 126 Mendoza-Quijano, 2007; Hammerson, 2007; Vasquez Díaz \& Quintero-Díaz, 2007; Hamerson,

127 Vazquez \& Quintero, 2013). Thus, knowledge regarding their ecological niche and their present

128 and future potential distribution is key to better understanding the causes of their population 129 decline. Moreover, due to the geological history and geographic position of the TMVB, the 130 animals of this region constitute a cenocron (a group of animals originated in a defined area that

131 have coexisted for a long period, thus sharing a common biogeographic history and a distribution 132 pattern; Halffter \& Morrone, 2017), therefore, changes in garter snake species' distributions in

133 the TMVB may represent future changes in other species' distributions of this region. We expect 134 that land use and climate change will reduce the future potential distribution of these five garter 135 snake species (i.e. a reduction in the suitable area available for each species). In this study, we 136 aimed to answer the following four questions. 1) Which climatic, topographic and land use 137 variables determine each species' distribution? 2) Considering land use and climate change, what 138 are the present and future potential distributions of each species? 3) What changes in suitable 139 available area in the TMVB will each species undergo in the future? 4) What changes in suitable 140 available area in the entire country will each species undergo in the future?

\section{Materials and methods:}

We modeled the potential distribution of the five Thamnophis species that occur in the TMVB (T. cyrtopsis, T. eques, T. melanogaster, T. scalaris, and T. scaliger). Occurrence records were obtained from fieldwork (60\% or more; Table S1) and online databases such as Global Biodiversity Information Facility (GBIF) and iNaturalist. We selected only the records from the last 20 years for the analysis, as extensive land use changes occurred in Mexico during the 1990s (FAO, 1993) and we included some land use variables (such as extent of induced grasslands and agriculture areas) in the analysis. Maps of occurrence data for all five species were generated to check for obvious errors. We also filtered these data to eliminate duplicated observations from

152 the same pixel (1-km resolution). We defined a polygon (background) for each species that 153 represents the accessibility area (Suárez-Atilano et al., 2014; Suárez-Atilano et al., 2017). These polygons were generated considering biogeographic regions with geographical records or records 
155 near their borders (Sunny, González-Fernández \& D’Addario, 2017). Three of the species are

156 endemic to Mexico and the other two have only a marginal distribution outside the country

157 (Rossman, Ford \& Seigel, 1996; Hammerson, 2013), therefore all polygons are large

158 representative regions of species distribution ranges. We obtained bioclimatic variables from

159 WorldClim (Hijmans et al., 2005); topographic and land cover variables were obtained from the

160 National Institute of Statistics and Geography (INEGI, 2013). We reclassified the land use map

161 (series V, 1:250000, generated during the period 2011 to 2013; INEGI, 2013) in different

162 exclusive classes that were converted to raster and transformed from categorical to continuous

163 using a resample method that averages the value of the surrounding pixels to assign a new value

164 to each pixel. All layers were processed in a raster format, with 1-km resolution, using ARC GIS

16510.5 and the packages RASTER (Hijmans, 2016) and RGDAL (Bivand, Keitt \& Rowlingson,

166 2017) for R software (version 3.4.0; R. Development Core Team, 2017). After a bibliographic

167 review and Pearson correlation analysis to discard highly correlated variables $\left(\mathrm{R}^{2}>0.8\right.$, Suárez-

168 Atilano, 2015) we selected the following variables: elevation, percent natural grasslands, percent

169 human-induced grasslands, percent arid vegetation, percent Pinus forest, distance to Pinus forest,

170 percent Quercus forest, distance to Quercus forest, percent Abies forest, distance to Abies forest,

171 distance to water sources, percent agriculture, minimum temperature of the coldest month,

172 maximum temperature of the warmest month, precipitation of the wettest month, and

173 precipitation of the driest month.

174 We used the maximum entropy modeling software (MAXENT; Phillips, Anderson \&

175 Schapire, 2006) which estimates species' distributions by finding the distribution of maximum

176 entropy (the most spread out, or closest to uniform), subject to constraints imposed by a known

177 distribution of the species, and by the environmental conditions across the study area (Anderson

178 \& González, 2011). First, we ran the model for each species in MAXENT with 10 replicates and

179 we selected the most important variables that explained the distribution of each species

180 (Anderson, Lew \& Peterson, 2003; Chefaoui, Hortal \& Lobo, 2005; Suárez-Atilano et al., 2017).

181 We only used linear and quadratic features because we had less than 80 records of T. scaliger

182 (Merow, Smith \& Silander, 2013) and, for an easier comparison, we used the same methodology

183 for all species. All analyses were performed using the logistic output for an easier interpretation

184 and a convergence threshold of $1 \times 10^{-5}$ with 500 iterations (Pearson et al., 2007; Suarez-

185 Atilano, 2015). We modeled again, this time with only the most important variables for each 
186 species (Guisan and Zimmerman, 2000; Guisan and Thuiller, 2005; Araújo and Guisan, 2006)

187 and projected these models to the future using both clumping (restricting the variables to the

188 range of values encountered during model calibration) and extrapolation methods (Merow, Smith

$189 \&$ Silander, 2013). We obtained the future bioclimatic variables CCSM4 for the year 2050

190 considering the climate change scenario rcp45 (middle-moderate) from WorldClim. Land use

191 and vegetation variables for the year 2050 were generated using the module LAND CHANGE

192 MODELER FOR ECOLOGICAL SUSTAINABILITY in IDRISI SELVA 17.0 software (Clark

193 Labs, 2012) and land use and vegetation layers from years 2002 and 2011 (series III and V;

194 INEGI 2005, 2013). We also used elevation, slope (obtained from the elevation layer), and

195 distance to urban settlements, for a better prediction of land use change. We designated present

196 urban areas (from the present distribution maps) and future urban areas (from the future

197 distribution maps) as areas of zero habitat suitability. We did not include distance to urban areas

198 as a variable in the models because this can generate a bias, as these areas are more easily

199 accessed by observers (Araujo \& Guisan, 2006). We generated present and future potential

200 distribution maps for each species. We preferred to show the continuous maps because binary

201 outputs can obscure important biological detail (Liu, White \& Newell, 2013). To evaluate model

202 performance, we used partial Receiving Operating Characteristic (partial ROC) analyses

203 (Peterson, Papes \& Soberón, 2008; Osorio-Olvera et al., 2016) as recommended based on

204 criticisms of area under the curve analyses (AUC) (Lobo, Jiménez-Valverde \& Real, 2008;

205 Peterson, Papes \& Soberón, 2008). While AUC evaluates only the environmental niche model

206 (under the omission-commission framework) performance, partial-ROC allows for statistical

207 significance from the AUC itself, based on a null distribution of expectations created via

208 bootstrapping replacement of $50 \%$ of the total available points and 1,000 resampling replicates

209 (Suárez-Atilano, 2015). One-tailed significance of the difference between AUC and the null

210 expectations was assessed by fitting a standard normal variate (the z-statistic) and calculating the

211 probability that the mean AUC ratio was $\leq 1$. We used $75 \%$ of occurrence localities for model

212 training and 25\% for model testing (Suarez-Atilano, 2015). We used the platform NICHE

213 TOOLBOX for partial-ROC calculations (Osorio-Olvera et al., 2016). We generated the species

214 potential distribution binary maps using Max SS threshold (Liu, White \& Newell, 2013), a

215 threshold selection method based on maximizing the sum of sensitivity and specificity. This is

216 considered an adequate method to use when reliable absence data are unavailable (Liu, White \& 
217 Newell, 2013). For each species, we used these binary maps to calculate the present and future

218 high-suitability areas (Suárez-Atilano, 2015) in both all of Mexico, and the TMVB only, to

219 assess whether the distribution of each species will decrease or increase in the future.

220

\section{Results}

222 After filtering the data, we worked with 267 records of T. cyrtopsis (Fig. 1A), 274 of T. eques

223 (Fig. 1B), 103 of T. melanogaster (Fig. 1C), 186 of T. scalaris (Fig. 1D), and 76 of T. scaliger

224 (Fig. 1E). The most important variables for each Thamnophis species are summarized in Table 1.

225 In all cases these variables together explained $60 \%$ or more of the species' potential distribution.

226 It is important to note that arid vegetation had an important negative effect on habitat suitability

227 for all species (Fig. S1) and the minimum temperature of the coldest month was important in

228 four of the five models. This latter variable was the most important to explain T. cyrtopsis

229 potential distribution, which was the species with the lowest tolerance to minimum temperatures

$230 \quad\left(5^{\circ} \mathrm{C}\right)$. Habitat suitability for $T$. scalaris and $T$. cyrtopsis steadily decreased when maximum

231 temperatures increased. Low agriculture percentages were positive for T. eques and $T$.

232 melanogaster but, at higher values (above 30\%), agriculture had a negative effect on habitat

233 suitability for both species. Elevation was the most important variable to explain T. eques and $T$.

234 melanogaster potential distribution. It was a positive variable for T. melanogaster, while habitat

235 suitability for T. eques was optimal near 2,500 m above sea level (masl). Distance to Abies

236 forests was the most important variable to explain $T$. scalaris and $T$. scaliger potential

237 distribution. It had negative effects on these species (as distance to Abies forests increase,

238 habitat suitability decrease), which means that proximity to Abies forests was positive for both

239 species. Distance to Quercus forests had a negative effect on habitat suitability for T. cyrtopsis,

240 which means that proximity to these forests was positive for the species.

242 Between 2002 and 2011, there was an increase of almost $16,000 \mathrm{~km}^{2}$ in agriculture and about $2435,000 \mathrm{~km}^{2}$ in urban areas (Fig. 2). There was also an increase in human-induced grasslands. A

244 reduction in arid vegetation and natural grasslands occurred, mainly because of its conversion to

245 agriculture lands. The area of Pinus and Quercus forests also fell, but Abies forests held steady.

246 For the year 2050, an increase of $82,865 \mathrm{~km}^{2}$ in agriculture areas is expected according to the

247 model (Fig. 3A, B). The urban areas will increase by $20,392 \mathrm{~km}^{2}$ (Fig. 3C, D), most of it taking 
248 place in the area around Toluca city (Fig. 3C, D), and induced grasslands will increase by 24,796 $249 \mathrm{~km}^{2}$ (Fig. 3E, F). Potential distribution maps for each species are in Fig. 4A-J. We found no 250 differences in future projections between extrapolation and clumping methods. Partial-ROC 251 bootstrap tests showed significant ratio values of empirical AUC over null expectations (mean 252 AUC ratios $\geq 1.5$ and p-values $<0.001$ in all cases; Fig. S1).

253 All species had a high proportion of their potential distribution in the TMVB. However, 254 according to high-suitability area calculations for present and future, all Thamnophis species will 255 experience reductions in their distribution in this region (Table 2). T. scaliger was only 256 distributed in the TMVB, while T. scalaris had a small part of its potential distribution in the 257 Sierra Madre del Sur. T. cyrtopsis, T. eques, and T. melanogaster were also distributed in the 258 Sierra Madre Occidental, Sierra Madre Oriental, Sierra Madre del Sur, and Oaxaca mountain 259 ranges. Unlike the TMVB, these biogeographic regions will not suffer important reductions in 260 suitable habitat for T. eques and T. melanogaster in the future. T. cyrtopsis will suffer important 261 reductions in all its potential distribution, which also includes Chiapas Highlands. The potential 262 distribution of T. melanogaster will increase in the future, considering the entire country, and $T$. 263 scalaris will suffer the biggest reduction of the five species (reductions of $54.08 \%$ for the 264 TMVB, and $54.30 \%$ for all of Mexico, Table 2; Fig. 4A-J).

265

266

\section{Discussion}

267

\section{Environmental variables}

269

270

271

Although current records and literature support the idea that grasslands and water sources are essential for Thamnophis species in Mexico (Jones, 1990; Manjarrez and Drummond, 1996; Venegas-Barrera and Manjarrez, 2011), these variables were not selected by the model as important to explain the distribution of the species. Both variables are more related to the microhabitat of the species, but for this study, we modeled the macrohabitat. Although most records of Thamnophis are in grasslands or near water sources (lakes, ponds and streams), these habitat features are present throughout most of the country, including areas where the species is not present, therefore, these variables are not limiting the species at a macro level. The percent of arid vegetation (which can be interpreted as the opposite of water sources) was a negative 
279 limiting factor for all species (Table 1). Distances to forests were more important for explaining 280 the presence of Thamnophis species than the percent of these forests. This was especially 281 important for T. scalaris and T. scaliger as distance to Abies forest was the most important 282 variable determining their potential distribution. These results are consistent with our fieldwork 283 observations, as we found only a few individuals inside forests; the majority were found in 284 grasslands near coniferous forests. This could be because coniferous forests occur in a moist $285\left(1,000-3,800 \mathrm{~mm}\right.$ annual precipitation) and cold microclimate $\left(2^{\circ}-24^{\circ} \mathrm{C}\right.$; Sáenz-Romero et al., 286 2012; Sunny, González-Fernández \& D’Addario, 2017) that is preferred by Thamnophis species 287 (Manjarrez \& Drummond, 1996). Therefore, microclimatic conditions of grasslands surrounded 288 by forests and large areas of grasslands without forest, may be different. Grasslands surrounded by forests offer the climatic benefits of forests (moist and cold), and the food benefits of grasslands (higher availability of small prey; Bastos, Araújo \& Silva, 2005; Mociño-Deloya et al., 2009; Reinert et al., 2011; Wittenberg, 2012; Mociño-Deloya, Setser \& Pérez-Ramos, 2014). Low percent of agriculture was positive for T. eques and T. melanogaster, but a high percent was negative for both species. This could be because agriculture is a tradeoff for many reptile species, especially snakes. It provides benefits for them, such as higher prey availability, but also exposes them to human interactions (i.e., people kill Thamnophis out of fear even though these species are not dangerous to humans; Sunny et al., 2015). Moreover, the persistent practice of crop burning and use of roller-chopping to prepare fields also affect their populations (Mullin \& Seigel, 2009).

Environmental temperature is important for ectothermic species like garter snakes because they are more active when they can maintain a body temperature above approximately $22^{\circ} \mathrm{C}$ (Manjarrez \& Drummond, 1996). Environmental temperature increases may lead Thamnophis to physiological stress that results in reduced fitness (Peterson, Gibson \& Dorcas 1993). The fact that T. cyrtopsis was limited by low and high temperatures could be the cause of its reduced potential distribution. The maximum temperature of the warmest month was one of the most important variables explaining $T$. scalaris potential distribution, however, for all other species, the minimum temperature of the coldest month was more important. This may be because $T$. scalaris is the species occurring at the highest elevation and, consequently, is adapted to a colder climate. Therefore, while other species are more limited by lower temperatures, $T$. scalaris is more limited by higher ones, which could make this species more vulnerable to 
310 warming temperatures associated with climate change. This scenario is consistent with the future

311 distribution model for this species as T. scalaris suffered the biggest reduction of the five

312 species. The fact that its distribution already includes the existing areas with the highest altitude

313 implies that, as climate change progresses, this species will be limited in its ability to shift its

314 distribution upward, increasing the possibility of becoming extinct (Sunny, González-Fernández

$315 \&$ D'Addario, 2017). According to the International Union for Conservation of Nature (IUCN),

316 T. scalaris is considered a species of Least Concern (Canseco-Márquez \& Mendoza-Quijano,

317 2007), however, our results suggest that this risk category is likely to change in the future.

318

319 Present and future potential distribution

320 The potential distribution of all species was located at high elevation areas (mountain ranges),

321 which is consistent with the biology of this genus (Rossman, Ford \& Seigel, 1996). The fact that

322 all species had a high proportion of their potential distribution in the TMVB means that this is a

323 very important biogeographic region for the conservation of these five Thamnophis species. This

324 is especially applicable for T. scalaris and T. scaliger as their suitable habitat was mainly found

325 in the TMVB. However, according to our models, all species will suffer large reductions in their

326 potential distribution in the TMVB, while in other regions some species like T. eques and $T$.

327 melanogaster will not. This may be because the TMVB is one of the most disturbed regions as it

328 contains the largest extent of urban area in Mexico (CONAPO, 2010). Considering the entire

329 country, all species will suffer reductions in their potential distributions in the future except $T$.

330 melanogaster. We are surprised by this fact, as this species is the most threatened of the five,

331 according to the IUCN (Endangered, Vasquez-Díaz \& Quintero-Díaz, 2007). This species is

332 more aquatic than the others (Manjarrez \& Drummond, 1996) and so, an approach that considers

333 both macrohabitat and microhabitat variables (such as water source and quality) may be

334 necessary for a better prediction of T. melanogaster potential distribution.

335

336 Conclusions and conservation implications

337 Arid vegetation has an important negative effect on habitat suitability for all species, and the

338 minimum temperature of the coldest month is important for four of the five species. T. cyrtopsis

339 has the lowest tolerance to minimum temperatures. Maximum temperature of the warmest month

340 is important for T. scalaris and T. cyrtopsis. Low percentages of agricultural areas are positive 
341 for $T$. eques and T. melanogaster but at higher values agriculture has a negative effect on habitat

342 suitability for both species. Elevation is the most important variable to explain T. eques and T.

343 melanogaster potential distribution while distance to Abies forests is the most important variable

344 to explain T. scalaris and T. scaliger potential distribution. As we predicted, all Thamnophis

345 species will experience reductions in their distributions in the TMVB, however, for the entire

346 country, T. melanogaster seems to increase its distribution in the future. We feel more studies

347 should be conducted to evaluate T. melanogaster distribution and abundance. These studies

348 should consider microhabitat variables such as water source and their quality. We also consider it

349 essential to carry out studies of $T$. scalaris abundance, as this species will suffer the biggest

350 reduction in potential distribution of the five species. Current abundance data of this species will

351 be key to decide if a change in its conservation status is needed. We are especially concerned

352 about our finding that a relatively abundant species like $T$. scalaris may suffer severe reductions

353 in its potential distribution, as this suggests that reptile species with similar distributions (such as

354 the lizard Barisia imbricate; Sunny, González-Fernández \& D’Addario, 2017) may undergo

355 similar reductions. For less abundant species with similar distributions (such as the rattlesnake

356 Crotalus triseriatus; Sunny et al., 2015), even larger reductions may result. Reductions in

357 suitable area available for Thamnophis and other species will cause the reduction and isolation of

358 their populations. Small populations are susceptible to demographic stochasticity (Gibbs, 1998;

359 Hicks \& Pearson, 2003) that can convert normal population fluctuations into local extinctions

360 (Gibbs 1998). Moreover, while certain isolation levels between populations may facilitate

361 precise evolutionary adaptations to local conditions (Tscharntke et al., 2012), the high isolation

362 levels affecting populations of many species in the TMVB, which are expected to increase in the

363 future and that are limiting species distributions to the highest altitudes of the volcanoes, will

364 lead to important losses of genetic diversity in these populations, thereby affecting their capacity

365 to cope with environmental changes and increasing their susceptibility to extinction (Johansson

366 et al., 2006; Sunny et al., 2014).

367

368 The TMVB has the highest area of Abies forests (91.14\%) of the country (Sunny, González-

369 Fernández \& D’Addario, 2017), however, it only represents $1.10 \%$ of TMBV area (Sunny,

370 González-Fernández \& D’Addario, 2017). Unfortunately, governmental laws have recently

371 changed the protection status of some areas of the TMVB, like the Nevado de Toluca Volcano 
372 (DOF, 2013). This change could lead to logging and changes in land use (Mastretta-Yanes et al., 373 2014). The extent of Abies forests have held steady from 2002 to 2011 (Fig. 2) but we are afraid

374 this could change as a consequence of this new protection status, thus affecting Thamnophis

375 populations and many other species. Moreover, land use changes are expected to accelerate due 376 to climate change (Maclean \& Wilson, 2011; Urban, 2015; Nadeau, Urban \& Bridle, 2017) so

377 garter snakes and other species of the TMVB could suffer the synergistic effect of both factors.

378 The process of reversing climate change involves world-wide economic systems and government 379 decisions, so there is little we can say about this here. However, we consider the conservation of

380 TMVB forests, especially Abies forests and grasslands associated with them, of great importance

381 for the conservation of many reptile and amphibian species that live in this region (Figueroa-

382 Rangel, Willis \& Olvera-Vargas, 2010; Vargas-Rodriguez et al., 2010; Ponce-Reyes et al., 2012;

383 Bryson et al., 2014). Moreover, in the short term, we think is essential to implement

384 environmental education activities to teach everyone the importance of our natural environments.

385 This in turn may lead to fewer reptiles being killed out of fear, and use of fewer wildlife-

386 destructive agricultural practices such as roller chopping and crop burning.

387

\section{Acknowledgments}

389 AGF is grateful to the graduate program "Doctorado en Ciencias Agropecuarias y Recursos

390 Naturales" of the Autonomous University of the State of Mexico and to the Consejo Nacional de 391 Ciencia y Tecnología. We thank Ruthe Smith for valuable comments and English review. We

392 thank the editor and two anonymous reviewers for their comments.

393

\section{References}

Anderson RP, González I Jr. 2011. Species-specific tuning increases robustness to sampling bias in models of species distributions: an implementation with Maxent. Ecological Modelling 222: 2796-2811.

Bastos EGDM, De Araújo AFB, Silva HR. 2005. Records of the rattlesnakes Crotalus durissus 
403

404

405

406

407

408

409

410

411

412

413

414

415

416

417

418

419

420

421

422

423

424

425

426

427

428

429

430

431

432

433

possible case of invasion facilitated by deforestation. Revista Brasileira de Zoologia 22: $812-815$.

Bivand R, Keitt T, Rowlingson B. 2017. rgdal: bindings for the geospatial data abstraction library.

Böhm M, Collen B, Baillie JE, Bowles P, Chanson J, Cox N, Rhodin, AG. 2013. The conservation status of the world's reptiles. Biological Conservation 157: 372-385.

Canseco-Márquez L, Mendoza-Quijano F. 2007. Thamnophis scalaris, Thamnophis scaliger. The IUCN Red List of Threatened Species 2007. Available at http://dx.doi.org/10.2305/IUCN.UK.2007.RLTS.T63992A12727613.en. (accessed 20 March 2018).

Cardinale BJ, Duffy JE, Gonzalez A, Hooper DU, Perrings C, Venail P, Kinzig AP. 2012. Biodiversity loss and its impact on humanity. Nature 486(7401): 59-67.

Castellano MJ, Valone TJ. 2006. Effects of livestock removal and perennial grass recovery on the lizards of a desertified arid grassland. Journal of Arid Environments 66: 87-95.

Chefaoui RM, Hortal J, Lobo J M. 2005. Potential distribution modelling, niche characterization and conservation status assessment using GIS tools: a case study of Iberian Copris species. Biological Conservation 122(2): 327-338.

Clark Labs. 2012. Idrisi 17: The Selva edition. Clark Photo Labs, Worcester, MA, USA.

CONAPO. 2010. Delimitación de las zonas metropolitanas de México. http://www.conapo.gob.mx/en/CONAPO/Zonas_metropolitanas_2010.

de Queiroz A, Lawson R, Lemos-Espinal JA. 2002. Phylogenetic relationships of North American garter snakes (Thamnophis) based on four mitochondrial genes: How much DNA sequence is enough? Molecular Phylogenetics and Evolution 22(2): 315-329.

Drummond H, Macías García C. 1989. Limitations of a generalist: a field comparison of foraging snakes. Behaviour 108:23-43.

Espinoza D, Ocegueda S. 2007. Introduccion. In: Biodiversidad de la Faja Volcánica Transmexicana. P. 5-6. Luna-Vega I, Morrone JJ, Espinosa D. Eds. México. Comisión Nacional para el Conocimiento y Uso de la Biodiversidad. Universidad Nacional Autónoma de México.

Figueroa-Rangel BL, Willis KJ, Olvera-Vargas M. 2010. Cloud forest dynamics in the Mexican Neotropics during the last 1300 years. Global Change Biology 16:1689-1704. 
434 Flores-Villela O, Canseco-Márquez L. 2007. , p. 407-420. Luna-Vega I, Morrone JJ, Espinosa D. 435 Eds. Comisión Nacional para el ConocimieRiqueza de la herpetofauna. In: Biodiversidad 436 de la Faja Volcánica Transmexicananto y Uso de la Biodiversidad/Universidad Nacional $437 \quad$ Autónoma de México, México.

438 Flores-Villela O. Canseco-Márquez L. Ochoa-Ochoa L. 2010. Geographic distribution and 439 conservation of the herpetofauna of the highlands of Central Mexico. In: Conservation of Mesoamerican Amphibians and Reptiles. p.303-321. Wilson LD, Towsend JH, Johnson JD. Eds.Eagle Mountain Publishing Co. Utah, USA.

Food and Agriculture Organization (FAO). 1993. Forest resources assessment 1990. Tropical countries. Forestry paper No. 112. Rome, FAO.

Gibbs JP. 1998. Distribution of woodland amphibians along a forest fragmentation gradient. Landscape Ecology 13:263-268.

Guisan A, Zimmerman NE. 2000. Predictive habitat distribution models in ecology. Ecological Modelling 135: 147-186.

Guisan A, Thuiller W. 2005. Predicting species distribution: offering more than simple habitat models. Ecology Letters 8: 993-1009.

Halffter G, Morrone JJ. 2017. An analytical review of Halffter's Mexican transition zone, and its relevance for evolutionary biogeography, ecology and biogeographical regionalization. Zootaxa 4226:1-46.

Hammerson GA. 2013. Thamnophis cyrtopsis. The IUCN Red List of Threatened Species 2013. Available at http://dx.doi.org/10.2305/IUCN.UK.2013-2.RLTS.T63975A3132338.en. (accessed 20 March 2018).

Hammerson GA, Vázquez Díaz J, Quintero Díaz GE. 2007. Thamnophis eques. The IUCN Red List of Threatened Species 2007. Available at http://dx.doi.org/10.2305/IUCN.UK.2007.RLTS.T63977A12732882.en. (accessed 20 March 2018).

Hicks NG, Pearson SM. 2003. Salamander diversity and abundance in forests with alternative land use histories in the Southern Blue Ridge Mountains. Forest Ecology and Management 177:117-130.

Hijmans RJ. 2016. raster: Geographic data analysis and modeling. Retrieved from https://cran.rproject.org/package=raster on 04/06/2017 
465 Huey RB. 1982. Temperature, physiology, and the ecology of reptiles. In: Biology of the

466

467

468

469

470

471

472

473

474

475

476

477

478

479

480

481

482

483

484

485

486

487

488

489

490

491

492

493

494

495

Reptilia. Physiology C. Physiological Ecology, vol. 12, p. 25-91. Gans C, Pough FH. Eds. Academic Press, New York.

INEGI, National Institute for Statistics and Geography. 2013. Conjunto nacional de uso de suelo y vegetación a escala 1:250000 Serie V; DGG-INEGI: México.

INEGI. 2005. Conjunto Nacional de Uso del Suelo y Vegetación a escala 1:250,000, Serie III, DGG-INEGI, México.

INEGI. 2012. Uso del suelo y vegetación escala 1:250.000 [Land use and vegetation scale 1:250.000]. Serie V, Información vectorial, Instituto Nacional de Estadística Geográfica e Informática, México.

Jimenez-Valverde A, Lobo JM. 2007. Threshold criteria for conversion of probability of species presence to either - or presence-absence. Acta Oecologica 31: 361-369.

Johansson M, Primmer CR, Merila J. 2006. History vs current demography: explaining the genetic population structure of the common frog (Rana temporaria). Molecular Ecology 15:975-983.

Jones KB. 1990. Habitat use and predatory behavior of Thamnophis cyrtopsis (serpenes: colubridae) in a seasonally variable aquatic environment. The Southwestern Naturalist 35 (2): 115-122.

Kortsch S, Primicerio R, Fossheim M, Dolgov AV, Aschan M. 2015. Climate change alters the structure of arctic marine food webs due to poleward shifts of boreal generalists. $\mathrm{Pr}$ oceedings of the Royal Society of London B: Biological Sciences 282: 1814.

Lathrop A, Jones JM, Alvarado-Díaz J, Grünwald CI, Murphy RW. 2014. Multilocus species delimitation in the Crotalus triseriatus species group (Serpentes: Viperidae: Crotalinae) with the description of two new species. Zootaxa 3: 475-496.

Liu C, White M, Newell G. 2013. Selecting thresholds for the prediction of species occurrence with presence-only data. Journal of biogeography 40(4): 778-789.

Lobo JM, Jiménez-Valverde A, Real R. 2008. AUC: misleading measure of the performance of predictive distribution models. Global Ecology and Biogeography 17: 145-151.

Maclean IM, Wilson RJ. 2011. Recent ecological responses to climate change support predictions of high extinction risk. Proceedings of the National Academy of Sciences 108(30): 12337-12342. 
496 Manjarrez J, Drummond H. 1996. Temperature-limited activity in the garter snake Thamnophis

497

498

499

500

501

502

503

504

505

506

507

508

509

510

511

512

513

514

515

516

517

518

519

520

521

522

523

524

525

526 melanogaster (Colubridae). Ethology 102:146-156.

Manjarrez J, Venegas-Barrera CS, García-Guadarrama T. 2007. Ecology of the Mexican alpine blotched garter snake (Thamnophis Scalaris). The Southwestern Naturalist 52 (2): 258262.

Manjarrez J. 1998. Ecology of the Mexican Garter Snake (Thamnophis eques) in Toluca, Mexico. Journal of herpetology 23: 464-46.

Mastretta-Yanes A, Moreno-Letelier A, Piñero D, Jorgensen TH, Emerson BC. 2015.

Biodiversity in the Mexican highlands and the interaction of geology, geography and climate within the Trans-Mexican Volcanic Belt. Journal of Biogeography 42(9): 15861600.

Mastretta-Yanes A, Quadri-Barba P, Escalante T, Arredondo-Amezcua L, Piñero D. 2014. Propuesta de cambios a la zonificación y modificaciones al Programa de Manejo del APFF Nevado de Toluca tras reunión de discusión con CONANP en diciembre 2013.

Merow C, Smith MJ, Silander JA. 2013. A practical guide to MaxEnt for modeling species' distributions: what it does, and why inputs and settings matter. Ecography 36: 10581069.

Mociño-Deloya E, Setser K, Pérez-Ramos E. 2014. Observations on the diet of Crotalus triseriatus (Mexican dusky rattlesnake). Revista Mexicana de Biodiversidad 85:12891291.

Montoya JM, Pimm SL, Solé RV. 2006. Ecological networks and their fragility. Nature 442: 259-264.

Mullin SJ, Seigel RA. 2009. Snakes: ecology and conservation. Cornell University Press.

Nadeau CP, Urban MC, Bridle JR. 2017. Coarse climate change projections for species living in a fine-scaled world. Global change biology 23(1): 12-24.

Osorio-Olvera L. 2016. NicheToolbox: A Web Tool for Exploratory Data Analysis and Niche Modeling.

Parmesan C, Yohe G. 2003. A globally coherent fingerprint of climate change impacts across natural systems. Nature 421(6918): 37-42.

Pearson RG. 2007. Species distribution modelling for conservation educators and practitioners. Bulletin of the American Museum of Natural History 3: 54-89. 
527 Peterson AT, Papes M, Soberón J. 2008. Rethinking receiver operating characteristic analysis 528 applications in ecological niche modelling. Ecological Modelling 213: 63-72.

529 Peterson CR, Gibson AR, Dorcas ME. 1993. Snake thermal ecology: the causes and 530 consequences of body-temperature variation. In: Snakes. Ecology \& behavior. Siegel RA, 531

532

533

534

535

536

537

538

539

540

541

542

543

544

545

546

547

548

549

550

551

552

553

554

555

556

557 Collins JT. Eds. New York: McGraw-Hill. Pp 241-314.

Phillips SJ, Anderson RP, Schapire RE. 2006. Maximum entropy modeling of species geographic distributions. Ecological Modelling 190: 231-259.

Ponce-Reyes R, Reynoso-Rosales VH, Watson JEM, VanDerWal J, Fuller RA, Pressey RL, Possingham HP. 2012. Vulnerability of cloud forest reserves in Mexico to climate change. Nature Climate Change 2: 448-452.

R, Development Core Team. 2017. R: A Language and Environment for Statistical Computing. R Foundation for Statistical Computing, Vienna, Austria. Web Site at http://www.rproject.org on May 1, 2017).

Reinert HK, MacGregor GA, Esch M, Bushar LM, Zappalorti RT. 2011. Foraging ecology of timber rattlesnakes Crotalus horridus. Copeia 3: 430-442.

Ribeiro R, Santos X, Sillero N, Carretero MA, Llorente GA. 2009. Biodiversity and land uses at a regional scale: is agriculture the biggest threat for reptile assemblages? Acta Oecologica 35: 327-334.

Rödder D, Engler JO. 2011. Quantitative metrics of overlaps in Grinnellian niches: advances and possible drawbacks. Global Ecology and Biogeography 20(6): 915-927.

Rossman DA, Ford NB, Seigel RA. 1996. The Garter Snakes: Evolution and ecology. Norman: OK, University of Oklahoma Press.

Russildi G, Arroyo-Rodríguez V, Hernández-Ordóñez O, Pineda E, Reynoso VH. 2016. Speciesand community-level responses to habitat spatial changes in fragmented rainforests: assessing compensatory dynamics in amphibians and reptiles. Biodiversity and conservation 25(2): 375-392.

Sáenz-Romero C, Rehfeldt GE, Duval P, Lindig-Cisneros RA. 2012. Abies religiosa habitat prediction in climatic change scenarios and implications for monarch butterfly conservation in Mexico. Forest Ecology and Management 275: 98-106.

Schneider-Maunoury L, Lefebvre V, Ewers RM, Medina-Rangel GF, Peres, CA, Somarriba E, Pfeifer M. 2016. Abundance signals of amphibians and reptiles indicate strong edge 
558

559

560

561

562

563

564

565

566

567

568

569

570

571

572

573

574

575

576

577

578

579

580

581

582

583

584

585

586

587

588

effects in Neotropical fragmented forest landscapes. Biological Conservation 200: 207215.

Seigel RA. 1996. Ecology and conservation of garter snakes: masters of plasticity. In: The garter snakes. Evolution and ecology. P. 55-89. Rossman DA, Ford NB, Seigel RA. Eds. Norman, University of Oklahoma Press.

Suárez-Atilano M, Burbrink F, Vázquez-Domínguez E. 2014. Phylogeographical structure within Boa constrictor imperator across the lowlands and mountains of Central America and Mexico. Journal of Biogeography 41: 2371-2384.

Suárez-Atilano M, Rojas-Soto O, Parra JL, Vázquez-Domínguez E. 2017. The role of environment on the genetic divergence between two Boa imperator lineages. Journal of Biogeography DOI: 10.1111/jbi.13006.

Suárez-Atilano M. 2015. Filogeografía de Boa Constrictor (Serpentes: Boidae) en México y Centro América. Tesis de Doctorado. Universidad Nacional Autónoma de México. Posgrado en Ciencias Biológicas. Instituto de Ecología.

Sunny A, González-Fernández A, D’Addario M. 2017. Potential distribution of the endemic imbricate alligator lizard (Barisia imbricata imbricata) in highlands of central Mexico. Amphibia-Reptilia 38 (2): 225-231.

Sunny A, Monroy-Vilchis O, Fajardo V, Aguilera-Reyes U. 2014. Genetic diversity and structure of an endemic and critically endangered stream river salamander (Caudata: Ambystoma leorae) in Mexico. Conservation Genetics 15:49-59.

Sunny A, Monroy-Vilchis O, Zarco-González MM, Mendoza-Martínez GD, Martínez-Gómez D. 2015. Genetic diversity and genetic structure of an endemic Mexican Dusky Rattlesnake (Crotalus triseriatus) in a highly modified agricultural landscape: implications for conservation. Genetica 143: 705-716.

Tscharntke T, Tylianakis JM, Rand TA, Didham RK, Fahrig L, Batary P, Bengtsson J, Clough Y, Crist TO, Dormann CF, Ewers RM. 2012. Landscape moderation of biodiversity patterns and processes eight hypotheses. Biological Reviews, 87(3): 661-685.

Urban MC. 2015. Accelerating extinction risk from climate change. Science 348(6234): 571-573. Uribe-Peña AZ, Ramirez-Bautista A, Casas-Andreu G. 1999. Anfibios y reptiles de las serranías del Distrito Federal, México. Cuadernos del Instituto de Biología 32. Universidad Nacional Autonoma de México. 
589 Vargas-Rodríguez YL, Platt WJ, Vázquez-García JA, Boqiun G. 2010. Selecting relict montane cloud forests for conservation priorities: the case of western Mexico. Natural Areas Journal 30:156-174.

592 Vázquez Díaz J, Quintero Díaz GE. 2007. Thamnophis melanogaster. The IUCN Red List of 593 Threatened Species 2007. Available at

594 http://dx.doi.org/10.2305/IUCN.UK.2007.RLTS.T63982A12725746.en. (accessed 20 595 March 2018).

596 Venegas-Barrera CS, Manjarrez J. 2011. Spatial patterns of species richness of garter snakes 597 Thamnophis in Mexico. Revista Mexicana de Biodiversidad 82: 179-191.

598 Warren DL, Glor RE, Turelli M. 2008. Environmental niche equivalency versus conservatism: 599 quantitative approaches to niche evolution. Evolution 62(11): 2868-2883.

600 Wittenberg RD. 2012. Foraging ecology of the Timber Rattlesnake (Crotalus horridus) in a 601 fragmented landscape. Herpetological Conservation and Biology 7: 449-461. 
Figure 1

Occurrence records used to build the distribution model for each Thamnophis species, showing the Trans-Mexican Volcanic Belt (TMVB) in dark gray. 

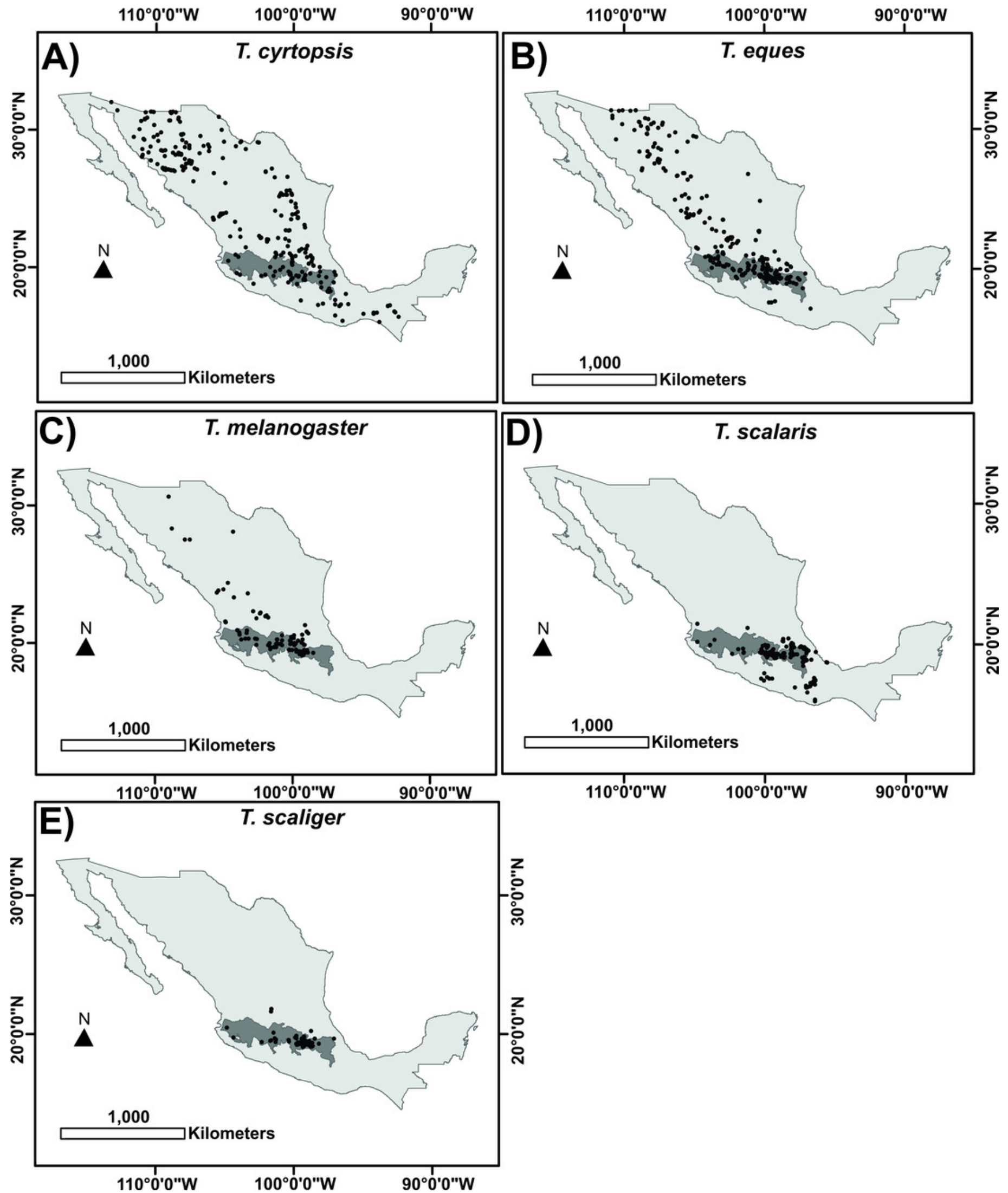
Figure 2

Land use change by category $\left(\mathrm{km}^{2}\right)$ between years 2002 and 2011.

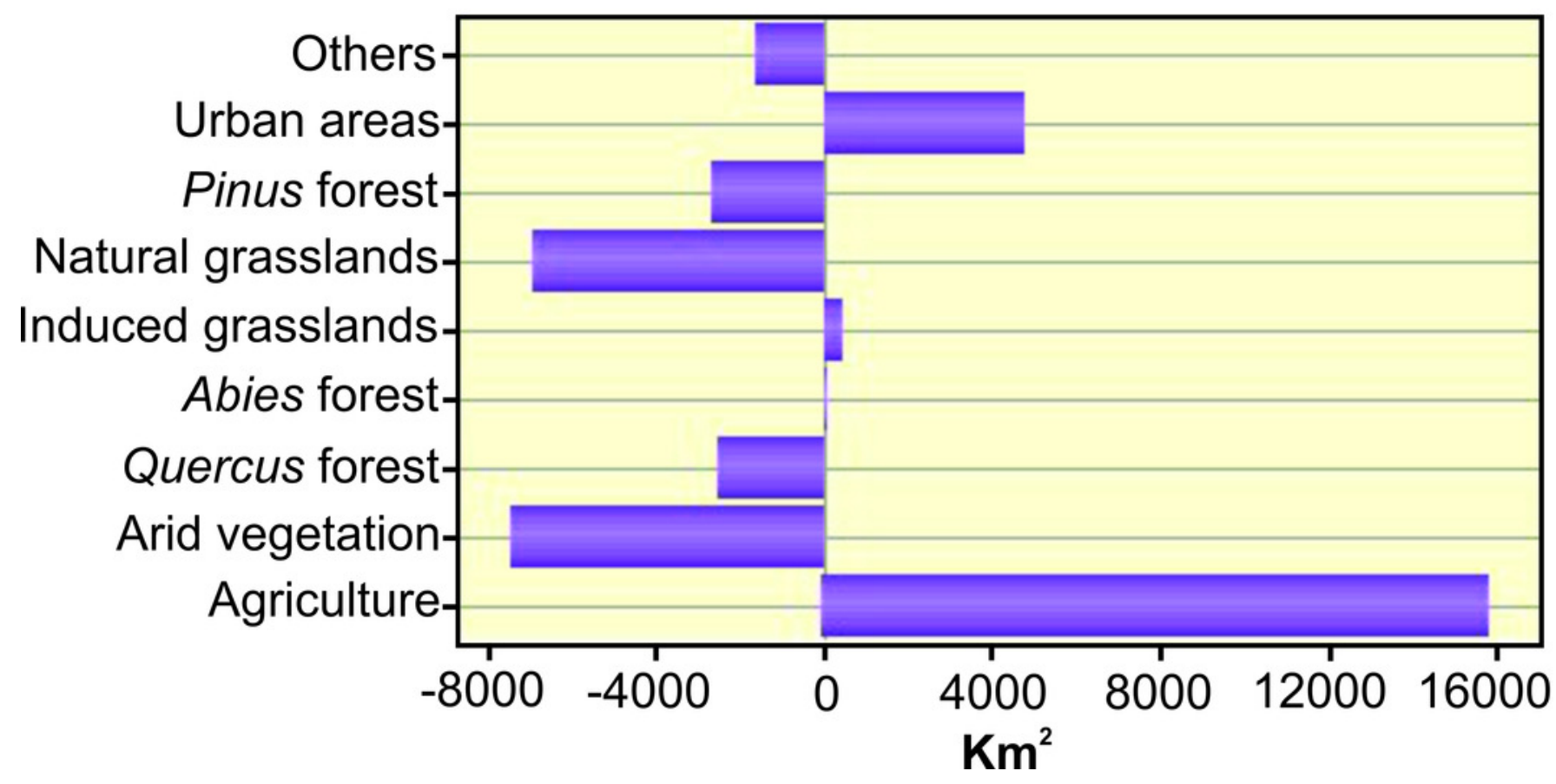


Figure 3

Present (2011) and future (2050) maps of (A, B) agriculture, in red; (C, D) urban, in gray; and $(E, F)$ induced grasslands, in orange. 

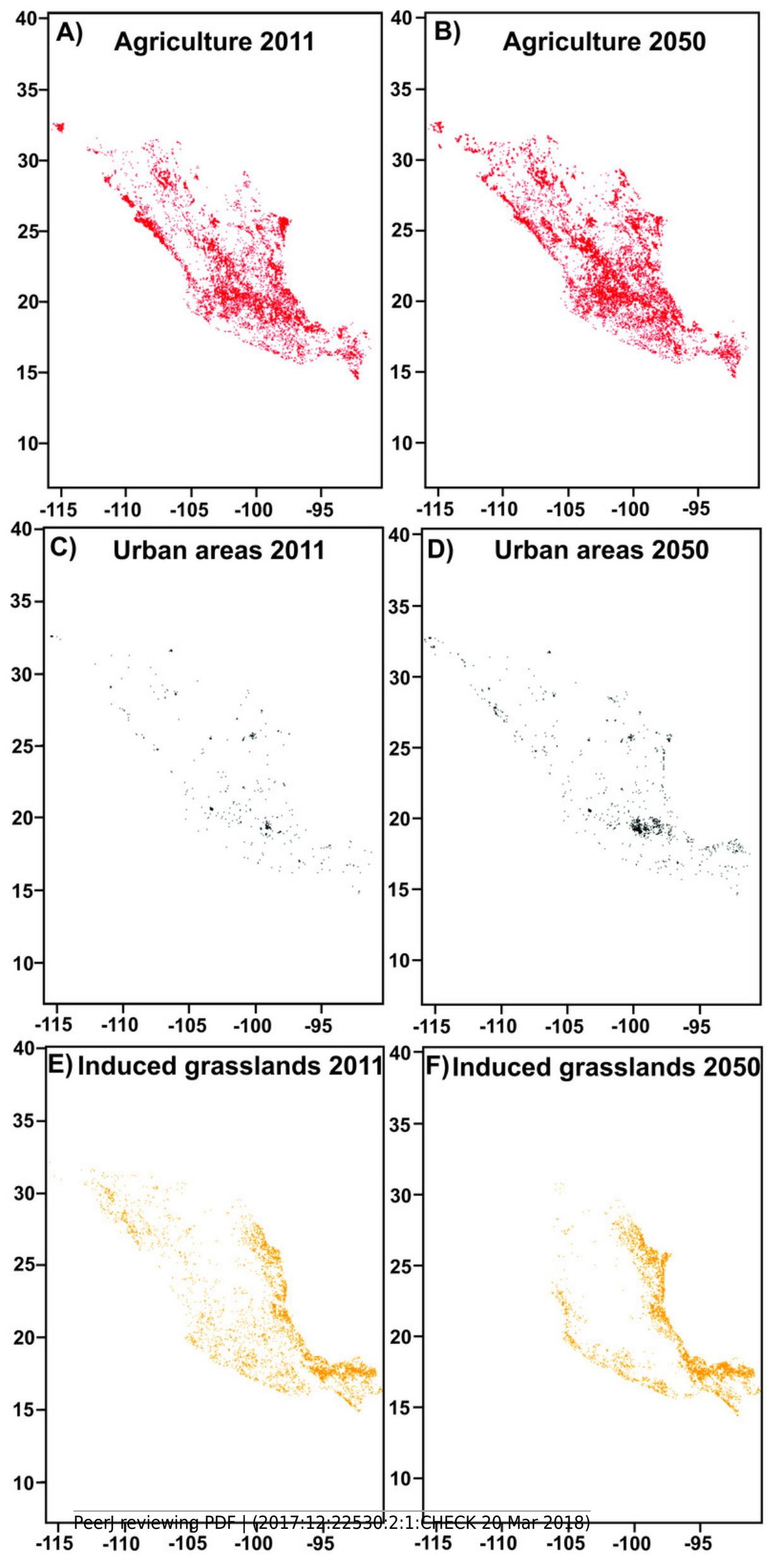


\section{Figure 4}

Present (2011) and future (2050) potential distribution maps for each Thamnophis species: (A, B) T. cyrtopsis, (C, D) T. eques, (E, F) T. melanogaster, $(G, H) T$. scalaris and (I, J) T. scaliger.
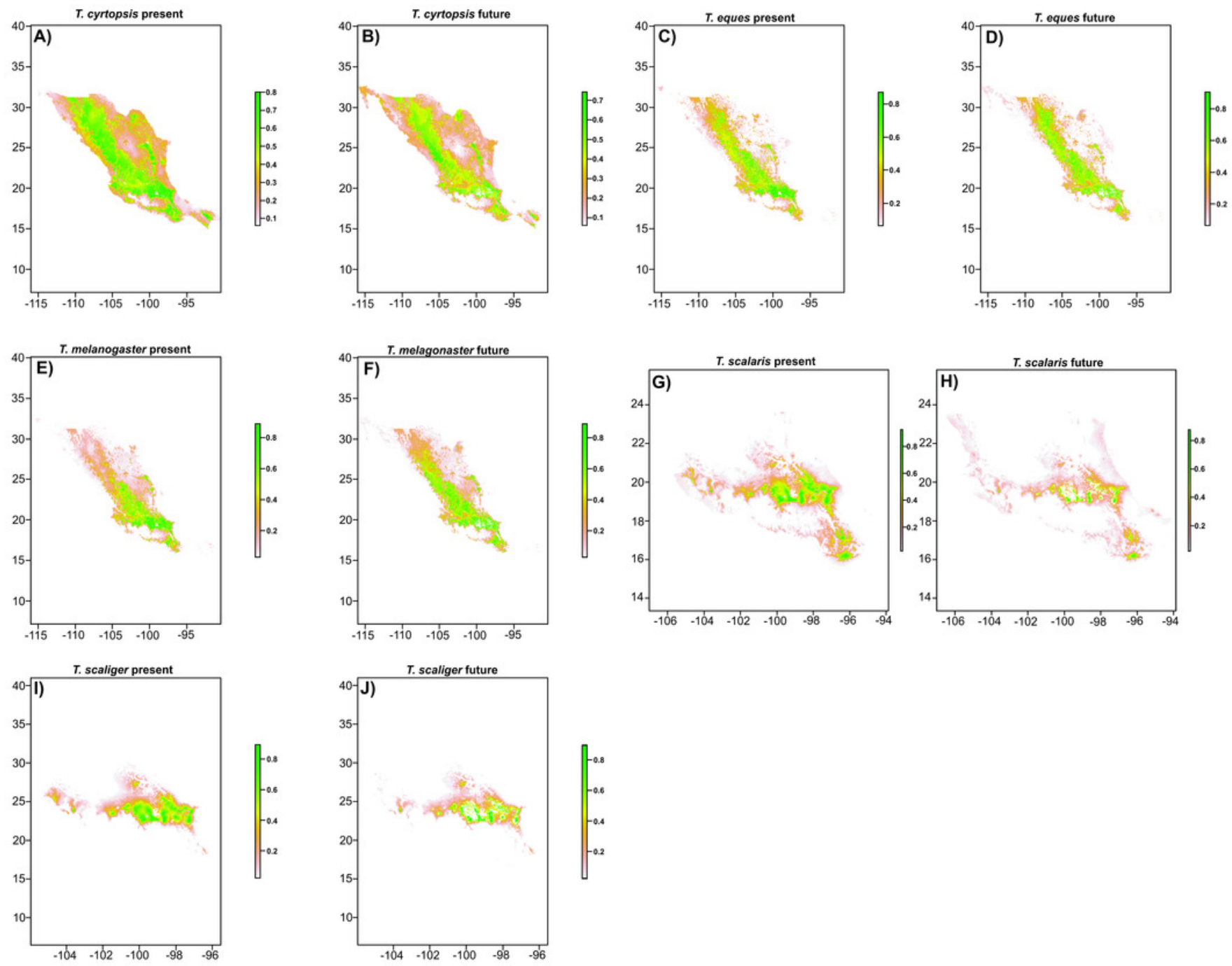


\section{Table $\mathbf{1}$ (on next page)}

Contribution percent of the most important variables that explain the distribution of each Thamnophis species. 
1

\begin{tabular}{|c|c|c|c|c|c|}
\hline Variables & T. cyrtopsis & T. eques & T. melanogaster & T. scalaris & T. scalige \\
\hline $\begin{array}{l}\text { Minimum temperature of } \\
\text { the coldest month }\end{array}$ & 33.7 & 19.2 & 11.3 & & 26.5 \\
\hline $\begin{array}{l}\text { Maximum temperature of } \\
\text { the warmest month }\end{array}$ & 5.2 & & & 36 & \\
\hline Elevation & & 28.4 & 27.3 & & \\
\hline $\begin{array}{l}\text { Arid vegetation } \\
\text { Agriculture }\end{array}$ & 26.4 & $\begin{array}{c}15.6 \\
9.6\end{array}$ & 11.5 & 4.9 & 5.3 \\
\hline Distance to Quercus forest & 8.5 & & 12.9 & & \\
\hline Distance to Abies forest & & & & 44.9 & 40.6 \\
\hline Total & 73.8 & 72.8 & 63 & 85.8 & 72.4 \\
\hline
\end{tabular}

\section{2}




\section{Table 2 (on next page)}

Present and future high suitability area $\left(\mathrm{km}^{2}\right)$ and percent of reductions in these areas for each Thamnophis species in Mexico and the Trans-Mexican Volcanic Belt (TMVB). 


\begin{tabular}{|c|c|c|c|c|c|c|}
\hline & \multicolumn{3}{|c|}{ MEXICO } & \multicolumn{3}{|c|}{ TMVB } \\
\hline & $\begin{array}{c}\text { Present } \\
\text { distribution } \\
\left(\mathbf{K m}^{2}\right)\end{array}$ & $\begin{array}{c}\text { Future } \\
\text { distribution } \\
\left(\mathbf{K m}^{2}\right)\end{array}$ & $\begin{array}{c}\text { Reduction } \\
\quad(\%)\end{array}$ & $\begin{array}{c}\text { Present } \\
\text { distribution } \\
\left(\mathbf{K m}^{2}\right)\end{array}$ & $\begin{array}{c}\text { Future } \\
\text { distribution } \\
\left(\mathbf{K m}^{2}\right)\end{array}$ & $\begin{array}{c}\text { Reduction } \\
(\%)\end{array}$ \\
\hline T. cyrtopsis & 661888.53 & 387393.67 & 41.47 & 103190.15 & 56172.18 & 45.56 \\
\hline T. eques & 583936.04 & 554336.36 & 5.07 & 102001.64 & 88928.44 & 12.82 \\
\hline T. melanogaster & 255647.78 & 317411.39 & -24.16 & 83237.55 & 67581.46 & 18.81 \\
\hline T. scalaris & 110441.63 & 50474.08 & 54.30 & 54057.65 & 24825.27 & 54.08 \\
\hline T. scaliger & 58682.16 & 37278.67 & 36.47 & 42804.76 & 26617.94 & 37.82 \\
\hline
\end{tabular}

